Journal of Engineering and Applied Sciences 14 (Special Issue 5): 8997-9004, 2019

ISSN: 1816-949X

(C) Medwell Journals, 2019

\title{
Evaluation and Improvement of Multi-lane Arterial Highway in Iraq
}

\author{
${ }^{1}$ Basim Jrew, ${ }^{2}$ Ahmed Hadi and ${ }^{3}$ Majed Msallam \\ ${ }^{1}$ Department of Civil Engineering, Isra University, Amman, Jordan \\ ${ }^{2}$ Engineering Project Management, Baghdad, Iraq \\ ${ }^{3}$ Department of Civil Engineering, Al-Balqa' Applied University, Amman, Jordan \\ Ahmed_hadi_92@yahoo.com
}

\begin{abstract}
Transportation industry is basically a service sector component. It is of great importance to traffic engineers and planners to understand and evaluate the quality of service provided by transport facilities. Highway Capacity Manual (HCM) with all its revisions, since, 1950 is the pioneer document in this area. It quantifies the concept of capacity for a transport facility and lays the foundations for estimating the Level of Service (LOS) being provided by that facility to its users. This study is an engineering project management. It is about evaluation and improving multi-lane highways in Iraq. The research study was conducted on one main multi-lane highway in Baghdad including Al- Dora intersection to Al- Rashid interchanges where this highway is considered as a major highway with high traffic volume in Iraq. HCS-2010 program software was used to evaluate and improve the level of service and traffic conditions for the highway for existing conditions (year of the study-2018) and short-term conditions (2023). Evaluation shows that all segments are operating at LOS E or LOS F for existing conditions, short-term conditions. The segments that operated at LOS E or LOS $\mathrm{F}$ for existing, short-term and mid-term conditions improvements are suggested by modifying the geometric and traffic conditions and changing the highway to a freeway facility; in order to operate at better LOS. Management flow diagrams were prepared for decision makers to be a guide for future planning programs.
\end{abstract}

Key words: Highway capacity, Highway Capacity Manual (HCM), multi-lane highway, Level of Service (LOS), Highway Capacity Software (HCS), conditions

\section{INTRODUCTION}

Roads and highways are a major part of the transportation infrastructure in Iraq and play a substantial role in the local economy and community development. High quality of service of these facilities is essential to ensure safe, cost-effective and daily traffic operations. There has been a rapid growth in the population of Iraq which led to an increase of demand in each and every aspect of our lives. Therefore, the increase of demand is directly proportional to the increase of the usage of vehicles and highway capacity. Highways in Iraq need to be reconsidered and future plans should be prepared to improve the quality of service of these facilities. With the growing number of vehicles, the quality of service decreased, so that, it became necessary to study the causes of the problem and find the appropriate solutions, either for the current or future conditions.

Updated HCM-2010 has been reorganized to make its contents more accessible and understandable. The reorganization is also intended to encourage analysts and decision makers to consider all roadway users as well as a broader range of performance measures when they assess transportation facility performance. HCM-2010 defines a multi-lane highway as a highway usually with two or three lanes in each direction with posted speed limits of $40-55 \mathrm{mi} / \mathrm{h}(60-90 \mathrm{~km} / \mathrm{h})$, divided by median or Two-Way Left Turn Lane (TWLTL). It could also be undivided with no control or partial control of access but may have periodic interruptions to flow at signalized intersections not closer than $3 \mathrm{~km}$. typically, multi-lane highways lead into central cities or along high-volume rural corridors connecting two cities or two activities. Multi-lane highways generally could be divided or undivided suburban multi-lane highways, suburban multi-lane highways with TWLTL or divided or undivided rural multi-lane highways (HCM, 2010).

Highway Capacity Software (HCS) was originally founded by the Federal HighWay Administration (FHWA) in 1986 as the Center for Microcomputers in Transportation (Mc Trans) which is now a full-service software support center associated with the University of Florida. HCS in general is a WINDOWS application with

Corresponding Author: Ahmed Hadi, Engineering Project Management, Baghdad, Iraq, Ahmed_hadi_92@yahoo.com 


\section{J. Eng. Applied Sci., 14 (Special Issue 5): 8997-9004, 2019}

an extensive help system and high level of professional technical support. HCS-2010 were developed in order to achieve the procedures defined in HCM-2010, to analyze capacity and determine Level Of Service (LOS) for signalized intersections, un-signalized intersections, urban streets (arterials), freeways, weaving areas, ramp junctions, multi-lane highways and two-lane highways (Anonymous, 2010).

Previous researches: Jerw et al. (2018), HCS-2000 and HCS-2010 software were used to evaluate the LOS for the management of multi-lane highways in Jordan for the existing condition (year 2014), short-term condition (year 2019) and mid-term condition (year 2024). The evaluation shows that some of the highway segments are operating at LOS-E or LOS-F for short-term and mid-term conditions (Jrew et al., 2018). Semeida (2013) explore the relationship between the road geometric characteristics and $\mathrm{HV}$ and LOS and capacity for rural multi-lane highways in Egypt using 45 different sites located in desert and agricultural highways; he found that the most influential variables on LOS and capacity in desert sites are $\mathrm{HV}$ then LW while in agricultural sites are LW then existence of number of access points.

Arun et al. (2013) present a review of significant methodological issues that need to be specifically addressed to enable accurate estimation of roadway capacity for multilane highways and methods that can deployed for roadway capacity estimation. They show that US-HCM methods developed in US are not directly applicable around the world. And how several countries have to developed their own versions of HCM.

James Robertson et al. developed procedures for calculating FFS on facilities with higher posted speed limits and methods for estimating LOS on multilane high ways with FFS up to $80 \mathrm{mi} / \mathrm{h}$. So that, for multilane highways with speeds $>60 \mathrm{mi} / \mathrm{h}$ they recommend to use Texas A\&M Transportation Institute (TTI) speed prediction equations to calculate BFFS and using the calculated FFS to determine LOS from speed-flow curves.

Yang and Zhang (2005), study the relationship between the number of lanes and the capacity of uninterrupted highway segments using statistical analysis. They show that the average capacity per lane decrease by increasing number of lanes on uninterrupted highway segments. They modify the assumption that average capacity per lane is equal on highways with different number of lanes proposed by many countries HCM; It requires that the manuals of highway capacity should be revised for the better plan and design of road network.

\section{MATERIALS AND METHODS}

Study area: The selected highway is of economical and cultural importance. It is an international highway that connects the major recreational and religious places in the Southern governorates to the capital city of Baghdad and connects the Southern governorates to the Northern governorates. Also, it connects the capital city of Baghdad with the province of Basra in the South and the province Al-Anbar in the West. The selected section of the multi-lane highway starts from Al-Dora intersection in Baghdad to Al-Rashid interchanges which are two branches with a length of $15 \mathrm{~km}$. The multi-lane highway connects the freeway system in Iraq to the expressway system in Baghdad City including International Baghdad Airport as shows in Fig. 1. The highway was divided to six segments, the segment boundary was determined based on traffic volume, number of access points, PHF and $\%$ of $\mathrm{HV}$.

Data collection: The data collected for the highway was divided into three types: road geometric data, vehicle speed data and traffic volume data. All the traffic data was collected by observation which is the main source of the data needed for this study. Through positioning of surveillance cameras at each section of the highway, necessary input data was obtained for evaluation and improvement. The Traffic Department at the Ministry of Interior was contacted to get the registered vehicles by state institutions in governmental, public and mixed sectors in order to obtain the yearly growth of traffic volume on Iraqi highways. Data on traffic volume collected in the past years shows that the number of vehicles increases with an annual growth rate $(\mathrm{g})$ of $6.2 \%$.

Field investigation of the study area was conducted several times in order to check the geometric and traffic data for the highway, define the highway segments and collect the data needed for the analysis. For data that could be collected, the ideal conditions and default values will be used as recommended by HCM. The posted speed limits were determined by observation for each segment. The Base Free Flow Speed (BFFS) will be estimated from the speed limit. According to, $\operatorname{HCM}(2010)$, the BFFS on multi-lane highways under base conditions is approximately the posted speed plus $5 \mathrm{mi} / \mathrm{h}(8 \mathrm{~km} / \mathrm{h})$ for a speed limit of $50 \mathrm{mi} / \mathrm{h}(80 \mathrm{~km} / \mathrm{h})$ or higher and the posted speed plus $7 \mathrm{mi} / \mathrm{h}(11 \mathrm{~km} / \mathrm{h})$ for speed limits $<50 \mathrm{mi} / \mathrm{h}$ $(80 \mathrm{~km} / \mathrm{h})$. The demand Volume under prevailing conditions (V) for the selected segments must be estimated and converted into the demand flow rate under equivalent base conditions $\left(\mathrm{V}_{\mathrm{p}}\right)$ in order to define the LOS 


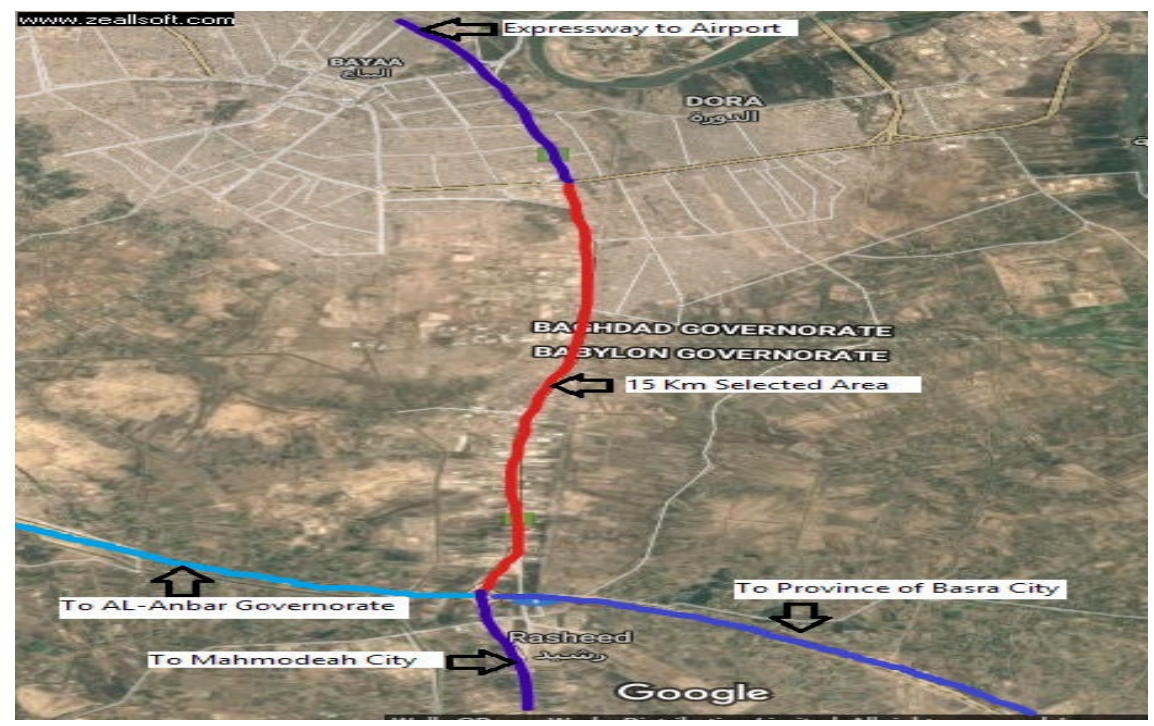

Fig. 1: Aerial photograph (screen shot) from Al-Dora intersection to Al-Rashid interchanges (Google earth program)

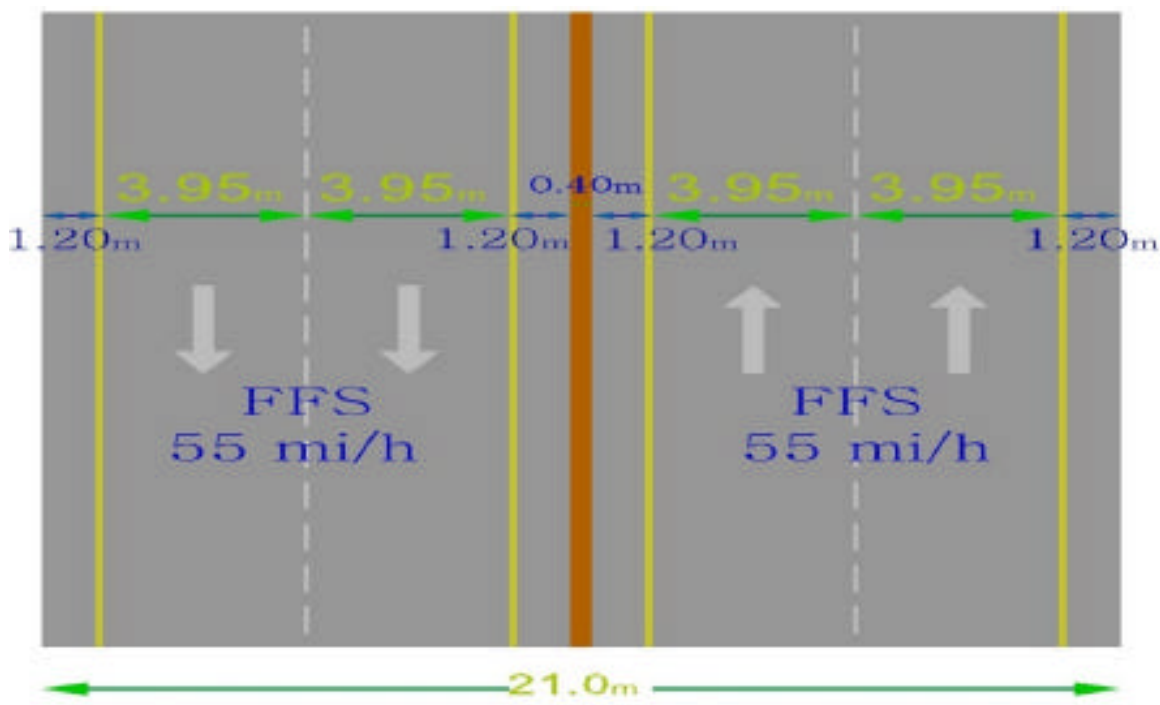

Fig. 2: Cross-section of the existing selected highway

for each segment. Maximum Peak hour volume (Phv) for each segment has been obtained from the traffic volume. Based on the Iraqi a code of highways, the left side of the highway is for the NB traffic direction and the right side of the highway is for the SB traffic direction. Therefore, all the access points have a sign as (L-exit) at the North direction and a sign as (R-exit) at the South direction. The geometric and volume input data for each segment in each direction of the selected highway were organized for the existing conditions (year, 2018) and short-term conditions (year 2023) as shown in Table 1 and 2. The highway from Al-Dora intersection to Al-Rashid interchanges is a rural multi-lane arterial highway with two lanes in each direction. The $12.95 \mathrm{ft}(3.95 \mathrm{~m})$ lane width for ach lane, shoulder width $3.9 \mathrm{ft}(1.2 \mathrm{~m})$ in each direction and the posted speed limit is $55 \mathrm{mi} / \mathrm{h}(88 \mathrm{~km} / \mathrm{h})$. The existing geometric cross-section of the highway is shown in Fig. 2. The following descriptions are given for each of the six segments of the highway. The existing geometric conditions of the multi-lane highway are improved by widening the cross-section $12 \mathrm{ft}(3.6 \mathrm{~m})$ in each direction and $6 \mathrm{ft}(1.8 \mathrm{~m})$ width of shoulder. The highway is converted from an undivided multi-lane highway into a divided multi-lane highway. So, the multi-lane highway becomes of three lanes in each direction as shown in Fig. 3. The HCS-2010 Sftware is in (US units); therefore, 
J. Eng. Applied Sci., 14 (Special Issue 5): 8997-9004, 2019

\begin{tabular}{|c|c|c|c|c|c|c|c|}
\hline Segment No. & Length (mi) & PHV (veh/h) & $\mathrm{HV} \%$ & PHF & Access Points AP (mi) & Posted speed (mi $/ \mathrm{h})$ & No. of lanes \\
\hline 1 & 1.20 & 3186 & 7.40 & 0.90 & 6 & 55 & 2 \\
\hline 2 & 1.30 & 2994 & 6.40 & 0.89 & 6 & 55 & 2 \\
\hline 3 & 2.36 & 3349 & 5.40 & 0.89 & 4 & 55 & 2 \\
\hline 4 & 0.98 & 3362 & 7.40 & 0.90 & 4 & 55 & 2 \\
\hline 5 & 1.60 & 2994 & 7.80 & 0.90 & 3 & 55 & 2 \\
\hline 6 & 1.53 & 3382 & 6.50 & 0.90 & 5 & 55 & 2 \\
\hline 1 & 1.20 & 3259 & 7.60 & 0.90 & 5 & 55 & 2 \\
\hline 2 & 1.30 & 3011 & 6.40 & 0.89 & 4 & 55 & 2 \\
\hline 3 & 2.36 & 3407 & 6.96 & 0.89 & 5 & 55 & 2 \\
\hline 4 & 0.98 & 3344 & 6.70 & 0.90 & 4 & 55 & 2 \\
\hline 5 & 1.60 & 2237 & 8.10 & 0.92 & 2 & 55 & 2 \\
\hline 6 & 1.53 & 3321 & 6.20 & 0.90 & 4 & 55 & 2 \\
\hline
\end{tabular}

*Lane width $=3.6 \mathrm{~m}(12 \mathrm{ft})$ as recommended for analysis as ideal condition by HCM

Table 2: Traffic and geometric data of each segment for Al-Dora intersection to Al-Rashid interchanges (after 5 years/2023) Al-Dora intersection to Al-Rashid interchanges

\begin{tabular}{|c|c|c|c|c|c|c|c|c|}
\hline \multicolumn{9}{|c|}{ Right side (NB) } \\
\hline Segment No. & Length (mi) & $\mathrm{PHV}$ (veh/h) & $\mathrm{HV} \%$ & PHF & Access Points AP (mi) & Posted speed (mi/h) & Lane ${ }^{*}$ width (ft) & No. of lanes \\
\hline 1 & 1.20 & 4303 & 10.00 & 0.90 & 6 & 55 & 12 & 2 \\
\hline 2 & 1.30 & 4048 & 8.60 & 0.89 & 6 & 55 & 12 & 2 \\
\hline 3 & 2.36 & 4524 & 7.30 & 0.89 & 4 & 55 & 12 & 2 \\
\hline 4 & 0.98 & 4541 & 10.00 & 0.90 & 4 & 55 & 12 & 2 \\
\hline 5 & 1.60 & 4045 & 10.50 & 0.90 & 3 & 55 & 12 & 2 \\
\hline 6 & 1.53 & 4568 & 8.80 & 0.90 & 5 & 55 & 12 & 2 \\
\hline \multicolumn{9}{|c|}{ Left Side (SB) } \\
\hline 1 & 1.20 & 4402 & 10.30 & 0.90 & 5 & 55 & 12 & 2 \\
\hline 2 & 1.30 & 4067 & 8.60 & 0.89 & 4 & 55 & 12 & 2 \\
\hline 3 & 2.36 & 4602 & 9.40 & 0.89 & 5 & 55 & 12 & 2 \\
\hline 4 & 0.98 & 4517 & 9.05 & 0.90 & 4 & 55 & 12 & 2 \\
\hline 5 & 1.60 & 3021 & 10.90 & 0.92 & 2 & 55 & 12 & 2 \\
\hline 6 & 1.53 & 4486 & 8.40 & 0.90 & 4 & 55 & 12 & 2 \\
\hline
\end{tabular}

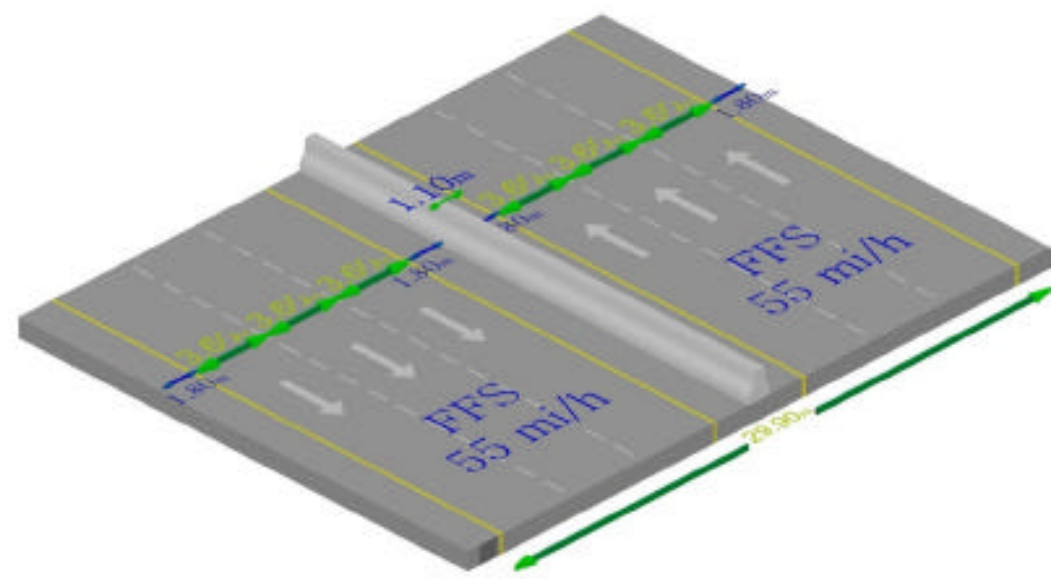

Fig. 3: Suggested cross section of the geometric conditions

the data is provided in both metric and US units for each segment. The data includes the length for each segment, the Peak Hour Volume (PHV), percent of grade (terrain), percent of heavy vehicles, density of Access Points $(\mathrm{AP} / \mathrm{mi})$, posted speed limit, Lane Width $(\mathrm{LW})$ and Number of Lanes in each direction (LN).

Finding: In this study, the existing traffic conditions at the selected highway (Al-Dora intersection to Al-Rashid interchanges) were evaluated to find out on which
Level of Service (LOS) it is expected to be operated in the future situation after 5 years (as short-term evaluation-2023). Also, it is important for decision makers to find out the possibility of improvement of each segment based on the updated HCM-2010 methodologies. HCS-2010 Software computer program were used in this study for compression and validation on each studied segment of the selected highway to develop more accurate management improvement programs. 


\section{RESULTS AND DISCUSSION}

According to, the Policy on Geometric Design of Highways and Streets, 2011, the guideline for level of service selection for rural highways is LOS-C (stable flow). The highest level of service is acceptable for some highway agencies such as LOS-D (approaching unstable flow). LOS-E (unstable flow or maximum capacity) and
LOS-F (forced or breakdown flow) are not acceptable traffic conditions and the highway segments should be improved to better LOS (AASHTO, 2011).

A lower level of service leads to significant environmental impacts on exposed persons living nearby and may interrupt with different activities in the surrounding area (Fig. 4). Such a condition is a major contributor to the increase in levels of unwanted gases

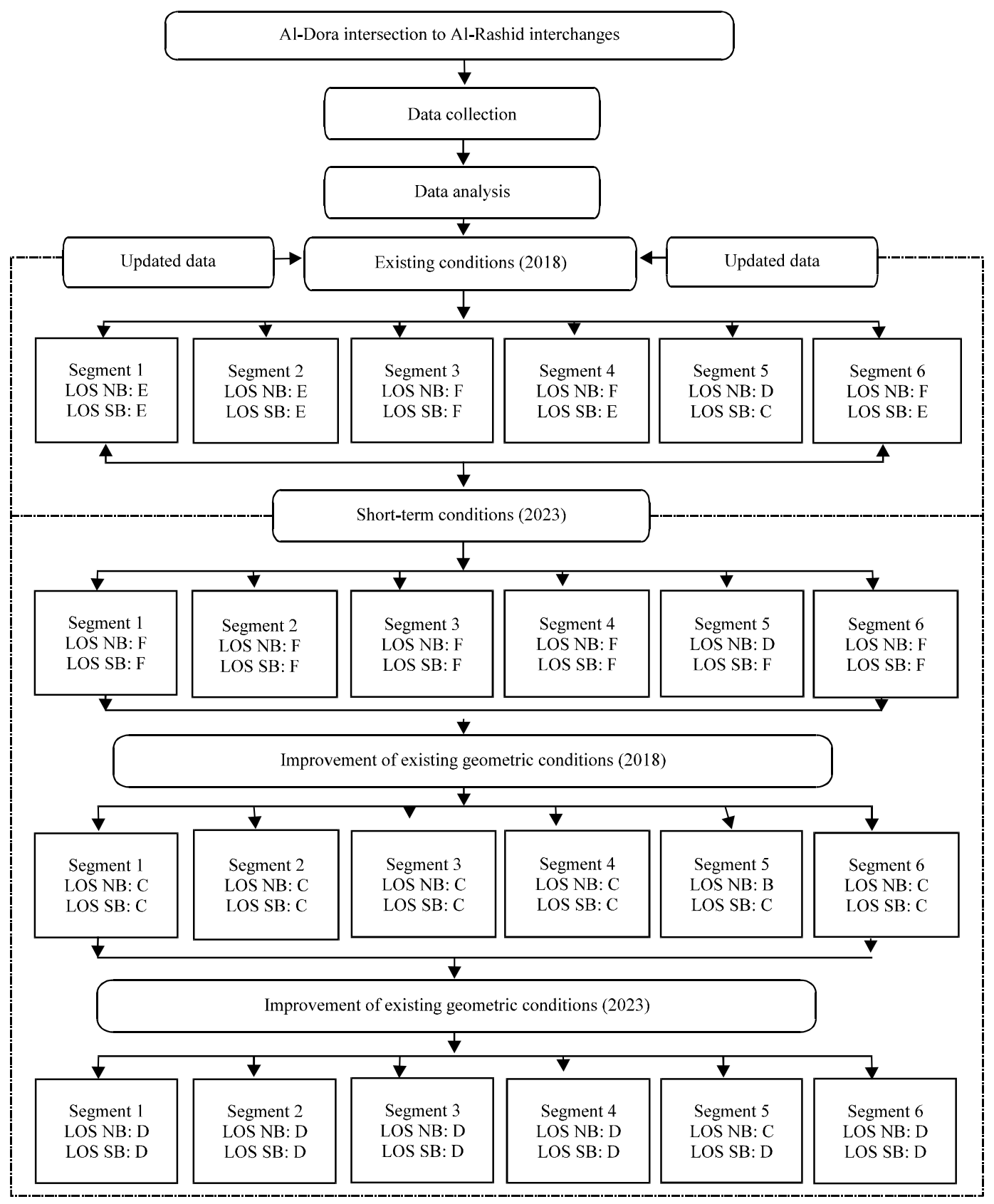

Fig. 4: Flow diagram of management components for Al-Dora intersection to Al-Rashid interchanges 
Table 3: Analy sis of results for existing conditions of the highway using HCS-2010 (year 2018)

\begin{tabular}{|c|c|c|c|c|c|c|}
\hline Segment No. & Direction & Flow rate $(\mathrm{Pc} / \mathrm{h} / \mathrm{ln})$ & FFS $(\mathrm{mi} / \mathrm{h})$ & Average travel speed $(\mathrm{mi} / \mathrm{h})$ & Density $(\mathrm{Pc} / \mathrm{mi} / \mathrm{ln})$ & LOS \\
\hline \multirow[t]{2}{*}{1} & Right & 1831 & 51.9 & 47.7 & 38.4 & $\mathrm{E}$ \\
\hline & Left & 1855 & 52.2 & 47.6 & 39.0 & $\mathrm{E}$ \\
\hline \multirow[t]{2}{*}{2} & Right & 1740 & 51.9 & 48.3 & 36.0 & $\mathrm{E}$ \\
\hline & Left & 1742 & 52.4 & 48.3 & 36.0 & $\mathrm{E}$ \\
\hline \multirow[t]{2}{*}{3} & Right & 1937 & 52.4 & - & - & $\mathrm{F}$ \\
\hline & Left & 1981 & 52.2 & - & - & $\mathrm{F}$ \\
\hline \multirow[t]{2}{*}{4} & Right & 1933 & 52.4 & - & - & $\mathrm{F}$ \\
\hline & Left & 1922 & 52.4 & 47.1 & 40.8 & $\mathrm{E}$ \\
\hline \multirow[t]{2}{*}{5} & Right & 1729 & 52.7 & 53.6 & 32.3 & $\mathrm{D}$ \\
\hline & Left & 1264 & 52.9 & 55.0 & 23.0 & $\mathrm{C}$ \\
\hline \multirow[t]{2}{*}{6} & Right & 1944 & 52.2 & - & - & $\mathrm{F}$ \\
\hline & Left & 1900 & 52.4 & 47.3 & 40.2 & $\mathrm{E}$ \\
\hline
\end{tabular}

Table 4: Analysis of results for short-term conditions of the highway using HCS-2010 (year 2023)

\begin{tabular}{|c|c|c|c|c|c|c|}
\hline Segment No. & Direction & Flow rate $(\mathrm{Pc} / \mathrm{h} / \mathrm{ln})$ & $\mathrm{FFS}(\mathrm{mi} / \mathrm{h})$ & Average travel speed $(\mathrm{mi} / \mathrm{h})$ & Density $(\mathrm{Pc} / \mathrm{mi} / \mathrm{ln})$ & LOS \\
\hline \multirow[t]{2}{*}{1} & Right & 2510 & 51.9 & - & - & $\mathrm{F}$ \\
\hline & Left & 2567 & 52.2 & - & - & $\mathrm{F}$ \\
\hline \multirow[t]{2}{*}{2} & Right & 2376 & 51.9 & - & - & $\mathrm{F}$ \\
\hline & Left & 2387 & 52.4 & - & - & $\mathrm{F}$ \\
\hline \multirow[t]{2}{*}{3} & Right & 2630 & 52.4 & - & - & $\mathrm{F}$ \\
\hline & Left & 2701 & 52.2 & - & - & $\mathrm{F}$ \\
\hline \multirow[t]{2}{*}{4} & Right & 2648 & 52.4 & - & - & $\mathrm{F}$ \\
\hline & Left & 2622 & 52.4 & - & - & $\mathrm{F}$ \\
\hline \multirow[t]{2}{*}{5} & Right & 2370 & 52.7 & - & - & $\mathrm{F}$ \\
\hline & Left & 1732 & 52.9 & 53.6 & 32.3 & $\mathrm{D}$ \\
\hline \multirow[t]{2}{*}{6} & Right & 2651 & 52.2 & - & - & $\mathrm{F}$ \\
\hline & Left & 2591 & 52.4 & - & - & $\mathrm{F}$ \\
\hline
\end{tabular}

due to increased amount of fuel burned in such area. The increase in number of vehicles due to poor LOS is usually associated with higher levels of pollutions such as gases, noises and psychological discomfort of nearby population. Furthermore, poor LOS results in an increase in traveling time which translates into an increase in the amount of fuel consumed by vehicles, thus lifting the traveling cost for highway users. The analysis of each segment of the highway in this study was conducted by using HCS-2010 for the existing and short-term conditions and for right direction (SB) and left direction (NB) in each segment. The results HCS-2010 are presented for the selected highway in Table 3 and 4 as shown. The analysis of the selected highway shows that all segments are operated at LOS-F or at LOS-E for the existing and short-term condition. In order to improve the LOS of all segments, some suggestions should be applied:

- Increasing the number of lanes from two in each direction to three in each direction

- Improving the geometric condition of the segment to ideal geometric condition in order to increase the Free Flow Speed (FFS)

- Changing the highway from an undivided multi-lane highway to a divided multi-lane highway

Based on the above suggestions, the output results shows improving the LOS from $\mathrm{E}$ or $\mathrm{F}$ to better LOS. Table 5 and 6 show the output results of improvement of all segments for existing and short-term periods. Segment will operate between LOS-C and LOC-D which are acceptable for both directions.

Development management program: The main requirement of this study is to improve the quality of service for the selected segments. This improvement is achieved by increasing the posted speed to the maximum safe speed and increasing the number of lanes in order to decrease density which in turn improves LOS (LOS F or LOSE) to better LOS (LOS C or LOSD). This improvement will lead to decrease conjunction, delay time, pollution and stopping time and increase safety for drivers with better travel time. The cost estimation for this improvement has to be carried out in order to determine the benefit to cost ratio.

The cost estimation is out of the scope of this study and is strongly recommended for any future work in this field. Management flow diagram is developed for the existing and short-term period planning based on the analysis, evaluation and improvement resulting from using HCS-2010 computer programs for the six segments of the selected Al-Dora intersection to Al-Rashid interchanges as shown in Fig. 4. The management flow diagram will assist decision makers to improve the breakdown traffic condition segments that operate at LOS-F or operate at maximum capacity (LOS-E) for existing planning (year 2018) and short-term planning (year 2023) during peak hour periods. 
J. Eng. Applied Sci., 14 (Special Issue 5): 8997-9004, 2019

Table 5: Improvement of existing conditions (year 2018)

\begin{tabular}{|c|c|c|c|c|c|c|}
\hline Segment No. & Direction & Flow rate $(\mathrm{Pc} / \mathrm{h} / \mathrm{ln})$ & FFS $(\mathrm{mi} / \mathrm{h})$ & Average travel speed $(\mathrm{mi} / \mathrm{h})$ & Density $(\mathrm{Pc} / \mathrm{mi} / \mathrm{ln})$ & LOS \\
\hline \multirow[t]{2}{*}{1} & Right & 1221 & 53.5 & 55 & 22.2 & $\mathrm{C}$ \\
\hline & Left & 1255 & 53.8 & 55 & 22.8 & $\mathrm{C}$ \\
\hline \multirow[t]{2}{*}{2} & Right & 1154 & 53.5 & 55 & 21.0 & $\mathrm{C}$ \\
\hline & Left & 1161 & 54.0 & 55 & 21.1 & $\mathrm{C}$ \\
\hline \multirow[t]{2}{*}{3} & Right & 1285 & 54.0 & 55 & 23.4 & $\mathrm{C}$ \\
\hline & Left & 1320 & 53.8 & 55 & 24.0 & $\mathrm{C}$ \\
\hline \multirow[t]{2}{*}{4} & Right & 1288 & 54.0 & 55 & 23.4 & $\mathrm{C}$ \\
\hline & Left & 1281 & 54.0 & 55 & 23.3 & $\mathrm{C}$ \\
\hline \multirow[t]{2}{*}{5} & Right & 1153 & 54.3 & 55 & 21.0 & $\mathrm{C}$ \\
\hline & Left & 842 & 54.5 & 55 & 15.3 & B \\
\hline \multirow[t]{2}{*}{6} & Right & 1296 & 53.8 & 55 & 23.6 & $\mathrm{C}$ \\
\hline & left & 1266 & 54.0 & 55 & 23.0 & $\mathrm{C}$ \\
\hline
\end{tabular}

Table 6: Improvement of short-term conditions (year 2023)

\begin{tabular}{|c|c|c|c|c|c|c|}
\hline Segment No. & Direction & Flow rate $(\mathrm{Pc} / \mathrm{h} / \mathrm{ln})$ & $\mathrm{FFS}(\mathrm{mi} / \mathrm{h})$ & Average travel speed $(\mathrm{mi} / \mathrm{h})$ & Density $(\mathrm{Pc} / \mathrm{mi} / \mathrm{ln})$ & LOS \\
\hline \multirow[t]{2}{*}{1} & Right & 1673 & 53.5 & 53.9 & 31.0 & $\mathrm{D}$ \\
\hline & Left & 1711 & 53.8 & 53.7 & 31.9 & $\mathrm{D}$ \\
\hline \multirow[t]{2}{*}{2} & Right & 1584 & 53.5 & 54.3 & 29.1 & $\mathrm{D}$ \\
\hline & Left & 1591 & 54.0 & 54.3 & 29.3 & $\mathrm{D}$ \\
\hline \multirow[t]{2}{*}{3} & Right & 1779 & 54.0 & 53.3 & 33.4 & $\mathrm{D}$ \\
\hline & Left & 1801 & 53.8 & 53.2 & 33.9 & $\mathrm{D}$ \\
\hline \multirow[t]{2}{*}{4} & Right & 1785 & 54.0 & 53.3 & 33.5 & $\mathrm{D}$ \\
\hline & Left & 1801 & 54.0 & 53.2 & 33.9 & $\mathrm{D}$ \\
\hline \multirow[t]{2}{*}{5} & Right & 1580 & 54.3 & 54.4 & 29.1 & $\mathrm{D}$ \\
\hline & Left & 1154 & 54.5 & 55 & 21.0 & $\mathrm{C}$ \\
\hline \multirow[t]{2}{*}{6} & Right & 1767 & 53.8 & 53.4 & 33.1 & $\mathrm{D}$ \\
\hline & Left & 1727 & 54.0 & 53.6 & 32.2 & $\mathrm{D}$ \\
\hline
\end{tabular}

\section{CONCLUSION}

From the application of updated HCM-2010 on the Al-Dora intersection to Al-Rashid interchanges, the following conclusions can be drawn: the existing conditions of the selected highway are operated on LOS-E and LOS-F, except for segment 5 for South Bound direction (SB) which is operating at LOS-C and North Bound direction (NB) which is operating at LOS-D. Short-term planning shows that segments $1,2,3,4$ and 6 for both North and South Bound directions (NB and SB) will operate at LOS-F, except for segment 5 for South Bound direction (SB) which is operating at LOS-D. Due to the improvement of management program, all segments will operate at LOS-C and LOS-D, except for segment 5 (SB) for existing condition which will operate at LOS-B. The improvement in LOS for the previous segments that are operating at LOS-E or LOS-F was due to modified geometric and traffic conditions such as: increasing the number of lanes in each direction to three lanes and changing the highway from an undivided multi-lane highway to a divided multi-lane highway increasing the posted speed limit in order to decrease the density and upgrading the prevailing geometric conditions to ideal geometric conditions. The developed flow diagram for management of Al-Dora intersection to Al-Rashid interchanges will assist decision makers in improving the highway to better LOS.

\section{RECOMMENDATIONS}

The following recommendations are suggested. It is recommended to use the methodology of $\operatorname{HCS} 2010$ for all major rural and suburban highways in Iraq in terms of operational analysis, design and planning. Increasing the number of lanes and the lane width as well as upgrading the geometric conditions to ideal conditions are recommended in future improvement planning, especially, for segments that are operating at LOS E or LOS F in Iraq. It is recommended to study other significant variables that affect the LOS including: horizontal curves, inside and outside lanes and combinations of horizontal and vertical curves. Traffic network management studies should be updated from time to time in order to take care of any major future changes in the traffic patterns or alternatives of the geometric network system. It is recommended to analysis for all segments on multi-lane highways in Iraq which are not included in this research.

The cost benefit analysis could be determined due to reduction in traffic congestion and improving LOS. Also the benefit due to reducing accidents, stops, delays and fuel consumption. Therefore, the cost estimation is out of the scope of this study and is highly recommended for future studies when the required data is available. It is recommended to develop and updated the growth factors of vehicles actually traveling on highways. It is 
recommended to build and maintain a historical database including the traffic volume data and geometric data for Iraq's highways. It is recommended to explore the relationship between road geometric characteristics and Heavy Vehicles (HVs), Level of Service (LOS) and capacity for rural multi-lane highways in Iraq.

\section{REFERENCES}

AASHTO., 2011. A Policy on Geometric Design of Highways and Streets. 6th Edn., American Association of State Highway and Transportation Officials, Washington, DC., USA., ISBN: 9781560515081, Pages: 912.

Anonymous, 2010. Traffic software integrated system. McTrans Center, Gainesville, Florida, USA. https://mctrans.ce.ufl.edu/featured/TSIS/
Arun, A., S. Velmurugan and M. Errampalli, 2013. Methodological framework towards roadway capacity estimation for Indian multi-lane highways. Proceedings of the 2nd International Conference of Transportation Research Group of India, Vol. 104, December 12-15, 2013, Agra in North India, Utter Pradesh, India, pp: 477-486.

HCM., 2010. Transportation Research Board (TRB). National Research Council, Washington, USA.

Jrew, B., N. Hussein and R. Al-Kouz, 2018. Management of multi-lane highways in Jordan (Case Study). Jordan J. Civ. Eng., 12: 10-21.

Semeida, A.M., 2013. New models to evaluate the level of service and capacity for rural multi-lane highways in Egypt. Alexandria Eng. J., 52: 455-466.

Yang, X. and N. Zhang, 2005. The marginal decrease of lane capacity with the number of lanes on highway. Proc. East. Asia Soc. Transp. Stud., 5: 739-749. 